\title{
Torque ripple and noise control of switched reluctance motor using an adaptive fuzzy PI control with the aid of AR algorithm
}

\author{
Rekha P. S. ${ }^{1}$, Vijayakumar T. ${ }^{2}$ \\ ${ }^{1}$ Department of Electrical and Electronics Engineering, SJB Institute of Technology, Bengaluru-560060, \\ ${ }^{2}$ Department of Electronics and Communication Engineering, SJB Institute of Technology, Bengaluru-560060, \\ Karnataka, and Affiliated to Visvesvaraya Technological University, Belagavi- 590018, Karnataka, India
}

\begin{tabular}{l} 
Article Info \\
\hline Article history: \\
Received Jan 17, 2021 \\
Revised Apr 3, 2021 \\
Accepted Apr 20, 2021 \\
\hline
\end{tabular}

\section{Keywords:}

Acoustic noise

Artificial raindrop algorithm

Direct torque control

Fuzzy gain scheduling

PI controller

PID controller

Switched reluctance motor

Torque ripple

\section{Corresponding Author:}

\section{Rekha P S}

Research Scholar

Department of Electronics and Communication Engineering

SJB Institute of Technology, Bengaluru-560060, Karnataka, India

Email: rekhas.venkatesh@gmail.com

\begin{abstract}
In recent days switched reluctance motor is widely used for numerous industrial applications due to its simple structure, minimum cost and maximum efficiency. Regardless of numerous exclusive benefits of the switched reluctance motor (SRM), acoustic noise of this motor is high and it is important to accomplish more analysis on the noise lessening, which is the primary goal of this paper. The major causes of acoustic noise in a SRM are torque ripple and radial magnetic force. Since radial magnetic force is highly influential by the design of motor, torque ripple control is analysed in this article for acoustic noise control. Torque ripple control of SRM is proposed using optimization in direct torque control (DTC) method. Nowadays, optimisation plays a crucial role in motor drives for enhanced control. In this paper, artificial raindrop algorithm is proposed in DTC of SRM to minimise torque ripple. Performance of proposed ARA based DTC of four-phase 8/6 SRM is analysed using Matlab and compared with the performance of fuzzy gain scheduling PI controller based DTC.
\end{abstract}

This is an open access article under the CC BY-SA license.

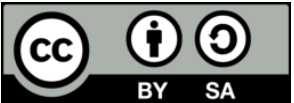

\section{INTRODUCTION}

Simple and strong structure, maximum efficiency, extensive speed range, flexible control and speedtorque characteristic of switched reluctance motor make it easier to meet various demands [1]. Because of the exclusive features of the SRM, it has been considered for different applications such as an electric vehicle [2]-[4], aerospace[5], [6], renewable energy [7]-[9], wheelchairs [10] and other automotive applications. In this analysis switched reluctance motor is proposed for electric vehicle application. Nevertheless, because of its rotor doubly salient structure and switching power source, torque ripple is enormous, and the noise and vibration are self-evident. Every one of these imperfections limit the use of the switched reluctance motor for electric /hybrid electric vehicles. Reduction in torque ripple leads to a reduction in acoustic noise of electric vehicle [11], [12]

Torque ripple of Switched Reluctance Motor is controlled using various strategies like Indirect torque control method, Direct Torque Control Method, Torque Sharing Function, Intelligent Control Techniques, Sliding Mode Control, Optimization Method, Converter Control and so on [13]. Among the numerous methods, DTC is an effective method of torque control which offers minimum torque ripple [14]. Hence in this paper DTC method is analysed for torque ripple control of 8/6 SRM. 
Many researchers analysed direct torque control of SRM using conventional PI and PID controller. Compared to traditional PI, PID controller artificial intelligent fuzzy logic controller in DTC offered improved dynamic performance of SRM presented a control approach depends on model predictive flux control is applied in the direct torque control (DTC) procedure for three-phase 12/8 SRM GA tuned PI in the DTC reduced the torque ripple effectively in comparison with DTC using PI and various other control methods. The survey states that advanced controllers in the application of DTC reduce torque ripple compared to a conventional controller [15-18]. Hence in this paper novel optimization artificial raindrop algorithm (ARA) is proposed in DTC to reduce maximum torque ripple to attain minimum noise. Performance of the proposed algorithm is compared with the fuzzy gain scheduling PI controller-based DTC under various speeds and load. Since both speed and torque performance of motor decides the quality of electric vehicle, in this article DTC based SRM drive along with noise control concentrates on above said parameters also.

\section{PROPOSED METHODOLOGY}

An asymmetrical converter is popularly used for the SRM drives as it has more switching states than the conventional converters [19]. In a direct torque control method, speed, and torque of SRM are controlled by a change in the sequence of a vector of the asymmetrical converter [20], [21]. Conventional PI controller in DTC results in reasonable torque ripple in SRM. Hence in this article, gains of PI controller are tuned using a fuzzy logic controller and proposed Artificial raindrop algorithm to attain precise torque reference.

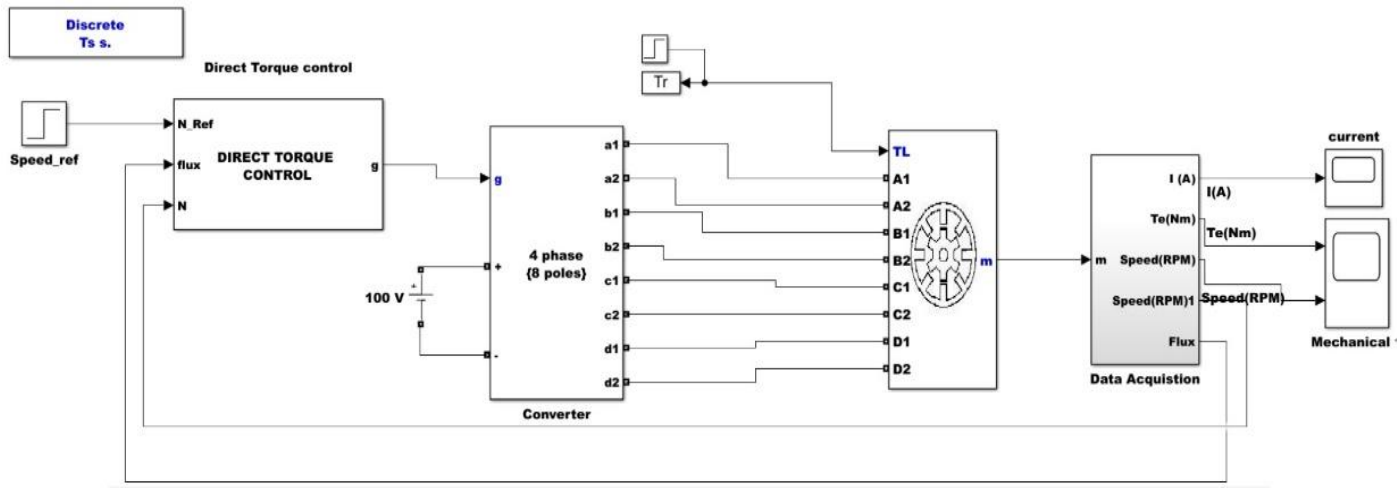

Figure 1. Schematic diagram of proposed controller

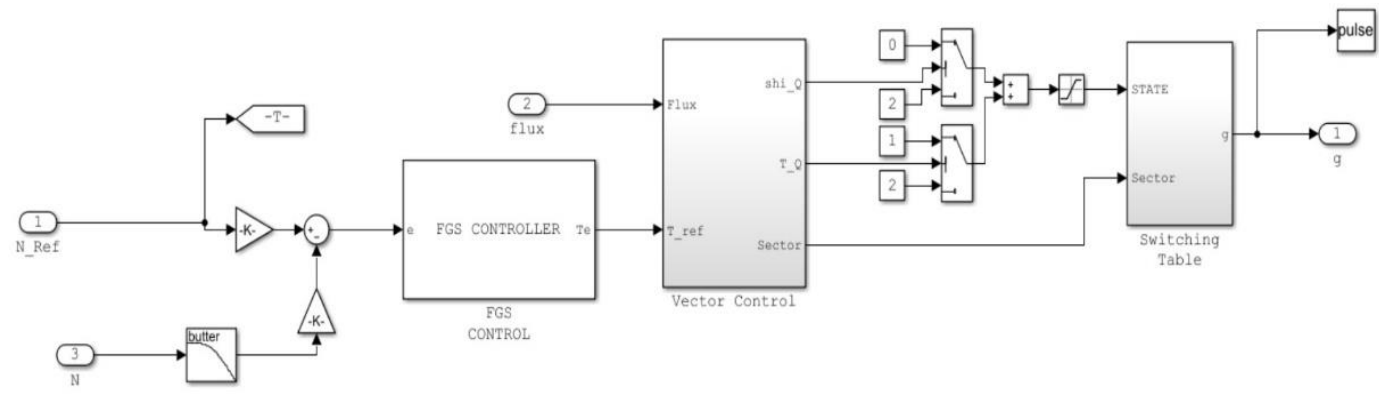

Figure 2. Schematic diagram of FGS in DTC

The electromechanical torque developed by the SRM [22] is given by

$$
T \approx i \boldsymbol{\partial} \boldsymbol{\Psi}(\boldsymbol{\theta}, i) / \boldsymbol{\partial} \boldsymbol{\Psi}(\boldsymbol{\theta})
$$

where $\boldsymbol{\Psi}(\boldsymbol{\theta})$ are the phase flux linkages as a function of rotor position $\theta$ and stator current $i$.

Fuzzy gain Scheduling PI Controller in DTC: The fuzzy logic controller is an artificial intelligent controller works like human thinking, capable of dealing nonlinear system and vague data [23-24]. Fuzzy 
gain scheduling controller offers online tuning of gains of the PI controller [25]-[30]. Mamdani method of fuzzy is proposed in this analysis with forty-nine rules to tune the gains of a PI controller and is shown Figure 2. Error $(\mathrm{E})$ in speed and rate of change in error $(\mathrm{Ec})$ are the two inputs to FGS to produce two outputs of $\mathrm{k}_{\mathrm{p}}$ and $\mathrm{k}_{\mathrm{i}}$. Both input and output variables comprise of seven triangular distributive functions. Negative big (NB), negative medium (NM), negative small (NS), zero (ZE), positive small (PS), positive medium (PM) and positive big (PB), are the functions of input and output variables. Fuzzy rules are shown in Table 2.

Based on input error with the help of rules in Table 2, FGS-PI controller changes $\mathrm{k}_{\mathrm{p}}$ and $\mathrm{k}_{\mathrm{i}}$, which decides the reference torque and results in the reduced torque ripple.

Table 2. Fuzzy rules

\begin{tabular}{|c|c|c|c|c|c|c|c|c|c|c|c|c|c|c|c|c|c|}
\hline \multicolumn{9}{|c|}{ Control rules for $\mathrm{k}_{\mathrm{p}}$} & \multicolumn{9}{|c|}{ Control rules for $\mathrm{k}_{\mathrm{i}}$} \\
\hline $\mathrm{E}$ & $\begin{array}{l}\mathrm{Ec} \\
\mathrm{Ki}\end{array}$ & NB & NM & NS & $\mathrm{ZE}$ & PS & PM & PB & $\mathrm{E}$ & $\begin{array}{l}\mathrm{Ec} \\
\mathrm{Kp}\end{array}$ & NB & NM & NS & $\mathrm{ZE}$ & PS & PM & PB \\
\hline & B & NB & NB & NM & NM & NS & $\mathrm{ZE}$ & $\mathrm{ZE}$ & & B & PB & PB & PM & PM & PS & ZE & $\mathrm{ZE}$ \\
\hline & M & NB & NB & NM & NS & NS & $\mathrm{ZE}$ & $\mathrm{ZE}$ & & NM & PB & PB & PM & PS & PS & ZE & NS \\
\hline & $S$ & NB & NM & NS & NS & ZE & PS & PS & & NS & PM & PM & PM & PS & $\mathrm{ZE}$ & NS & NS \\
\hline & $\mathrm{E}$ & NM & NM & NS & $\mathrm{ZE}$ & PS & PM & PM & & $\mathrm{ZE}$ & PM & PM & PS & $\mathrm{ZE}$ & NS & NM & NM \\
\hline & S & NM & NS & $\mathrm{ZE}$ & PS & PS & PM & PB & & PS & PS & PS & $\mathrm{ZE}$ & NS & NS & NM & NM \\
\hline & M & $\mathrm{ZE}$ & $\mathrm{ZE}$ & PS & PS & PM & PB & PB & & PM & PS & $\mathrm{ZE}$ & NS & NM & NM & NM & NB \\
\hline & $\mathrm{B}$ & $\mathrm{ZE}$ & ZE & PS & PM & PM & PB & PB & & PB & $\mathrm{ZE}$ & $\mathrm{ZE}$ & NM & NM & NM & $\mathrm{NB}$ & $\mathrm{NB}$ \\
\hline
\end{tabular}

\subsection{Artificial raindrop algorithm tuned PI controller in DTC}

Artificial raindrop algorithm follows the varying procedure of a raindrop [31]. In this procedure raindrops are assumed as objects and function of object is evaluated by relating elevation. The position of the lowermost altitude relates to the best solution. In this analysis minimisation of ITAE of speed error is considered as the fitness function to find optimum values $\mathrm{k}_{\mathrm{p}}$ and $\mathrm{k}_{\mathrm{i}}$. The entire recurring procedure of this algorithm is classified into six steps: raindrop generation, raindrop descent, raindrop collision, raindrop flowing, RP updating and vapour updating.

ARA initiates with the preliminary population by arbitrarily employing $N$ vapours in a hunting space, and each vapour has a consistent position stated below:

$$
\operatorname{Vapor}_{i}=\left(x_{i}^{(1)}, \ldots, x_{i}^{(d)}, \ldots x_{i}^{(D)}\right), i=1,2, \ldots N
$$

In (2) size of population is $\mathrm{N}$, problem dimension is $D$, and in the $d$ th dimension, location of the $i$ th vapour is $x_{i}^{(d)}$

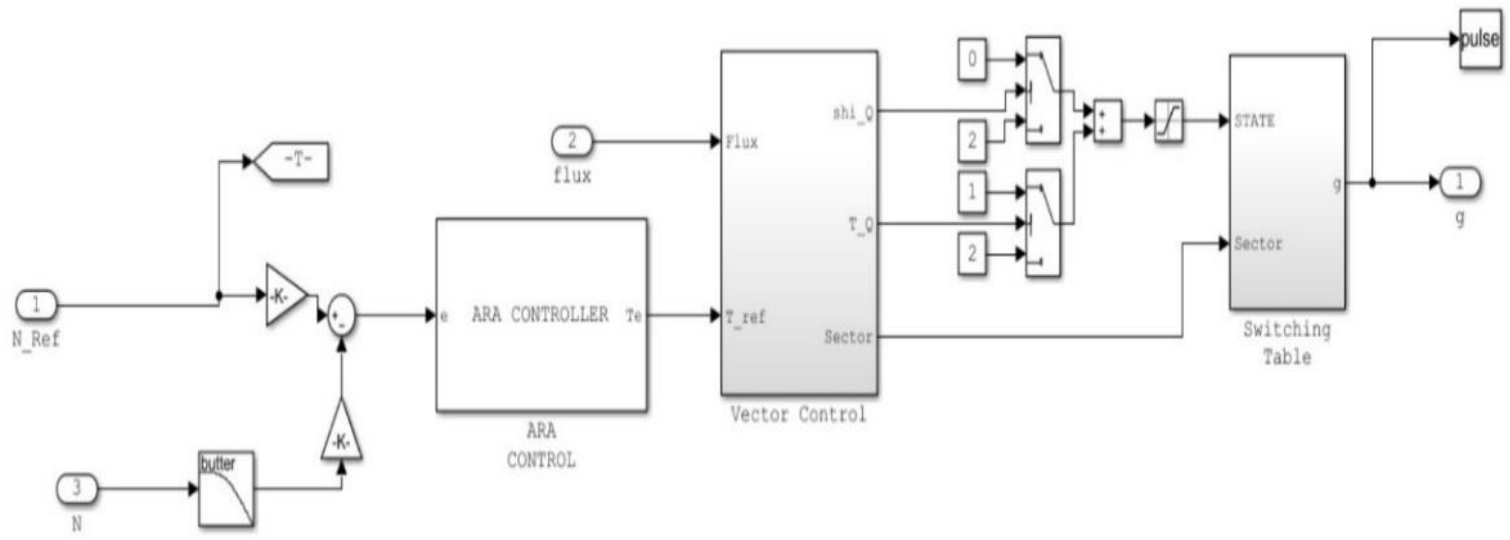

Figure 3. Schematic diagram of ARA controller.

\subsubsection{Raindrop generation}

It is expected, for effortlessness, that the raindrop location is the mathematical focus of ambient water vapour. In this way, its location can be characterized as:

$$
R D=\left(\frac{1}{N} \sum_{i=1}^{N} x_{i}^{(1)}, \ldots, \frac{1}{N} \sum_{i=1}^{N} x_{i}^{(d)}, \ldots \frac{1}{N} \sum_{i=1}^{N} x_{i}^{(D)}\right)
$$




\subsubsection{Raindrop descent}

At the point when the impact of outside elements is disregarded, the RD falls from the raincloud to the earth over descend. This suggests that one part of RD location is altered and the RD transfers to another position signified New RD. Consequently, the New RD is expressed as in (4):

$$
N e w_{R D^{(d)}}=R D^{\left(d_{2}\right)}+\varphi \cdot\left(R D^{\left(d_{3}\right)}-R D^{\left(d_{4}\right)}\right), \text { ifd }=d_{1} ; N e w_{-} R D^{(d)}=R D^{(d)}
$$

In an expression (4) $\varphi$ is a arbitrary number in the boundary of $(-1,1), d=1,2, \cdots, D$.

\subsubsection{Raindrop collision}

At the point when the $N e w_{-} R D$ reaches the floor; it is separated into various little RDs because of the speed and quality. At that point, these small raindrops $\left(S m a l l \_R D_{i}, \mathrm{i}=1,2, \cdot, \mathrm{N}\right)$ are flying in entire possible directions. Hence, $S m a l l \_R D_{i}$ can be planned beneath:

$$
S m a l l_{-} R D_{i}=N e w_{-} R D+\operatorname{sign}(\alpha-0.5) \cdot \log (\beta) \cdot\left(N e w_{-} R D-\operatorname{Vapor}_{k}\right)
$$

where $k$ is arbitrarily selected index from the set $\{1,2, \cdots, N\}, \alpha$ and $\beta$ both are regularly dispersed arbitrary numbers in the boundary of $(0,1)$ and sign () defines for sign function.

\subsubsection{Raindrop flowing}

As per the activity of gravity, these Small_ $\mathrm{RD}_{\mathrm{i}}(\mathrm{i}=1,2, \cdot, \mathrm{N})$ passes from topmost height to low elevation course, and the majority of them will inevitably stop at the areas with lower height (for example the better arrangements). In the procedure of algorithm development, these better arrangements can give extra data about the hopeful advancement direction. Therefore, the raindrop pool (RP) is intended to follow these lower locations found up to now throughout the pursuit, and the refreshing of RP is implemented as follows:

1) RP is started to be any attainable result of hunt space.

2) The best result of the present population is accumulated to RP subsequently every repetition.

3) On the off chance that the size of RP surpasses the limit given, at that point a few solutions in RP will be arbitrarily erased to retain the extent of RP unchanging and diminish computation sum.

Furthermore, the streaming direction of raindrop di for Small_RDi $(\mathrm{i}=1,2, \cdot, \mathrm{N})$ is built dependent on the linear mix of dual vectors $\mathrm{d} 1_{\mathrm{i}}$ and $\mathrm{d} 2_{\mathrm{i}}$, in which $\mathrm{d}_{\mathrm{i}}, \mathrm{d} 1_{\mathrm{i}}$ and $\mathrm{d} 2_{\mathrm{i}}$ are portrayed as:

$$
\begin{aligned}
& d 1_{i}=\operatorname{sign}\left(F\left(R P_{k 1}\right)-F\left(\text { Small_}_{-} R D_{i}\right)\right) \cdot\left(R P_{k 1}-S m a l l_{-} R D_{i}\right) \\
& d 2_{i}=\operatorname{sign}\left(F\left(R P_{k 2}\right)-F\left(\text { Small_}_{-} R D_{i}\right)\right) \cdot\left(R P_{k 2}-S m a l l_{-} R D_{i}\right) \\
& d_{i}=\tau_{1} \cdot \operatorname{rand} 1_{i} \cdot d 1_{i}+\tau_{2} \cdot \operatorname{rand} 2_{i} \cdot d 2_{i}
\end{aligned}
$$

In an expressions (11- 12) $\mathrm{RP}_{k 1}$ and $\mathrm{RP}_{k 2}$ are any deuce of applicant solutions in $\mathrm{RP}(k 1, k 2 \in\{1,2, \cdot$ . ., $|\mathrm{RP}|\}), \tau_{1}$ and $\tau_{2}$ are two-step parameters of Small_RD $\mathrm{R}_{i}$ flowing, rand $1 i$ and rand $2 i$ both are consistently disseminated arbitrary numbers within a boundary of $(0,1), \mathrm{F}(\cdot)$ denoted fitness function.

Consequently, New Small_RD $\operatorname{RD}_{i}(i=1,2, \cdots, N)$ is stated as:

$$
\text { NewSmall_R } D_{i}=S m a l l \_R D_{i}+d_{i}
$$

Be that as it may, the Small_RD $\mathrm{RD}_{i}$ not able to pass in an actual atmosphere. It is essential to present a constraint max flow number to regulate the extreme quantity of flows. Subsequently, they will remain in the areas with a moderately lesser height or dissipate subsequently a few streaming.

\subsubsection{Vapour updating}

Eventually, the vapour disappears in the air by vanishing and additionally develop the new raindrop. To enhance the working recital and convergence proportion of ARA, in the process of vapour apprising, the $N$ finest results from new small RD $U$ vapour are nominated by means of the sorting technique as the subsequent vapour population. Flowchart of ARA is shown in Figure 5 


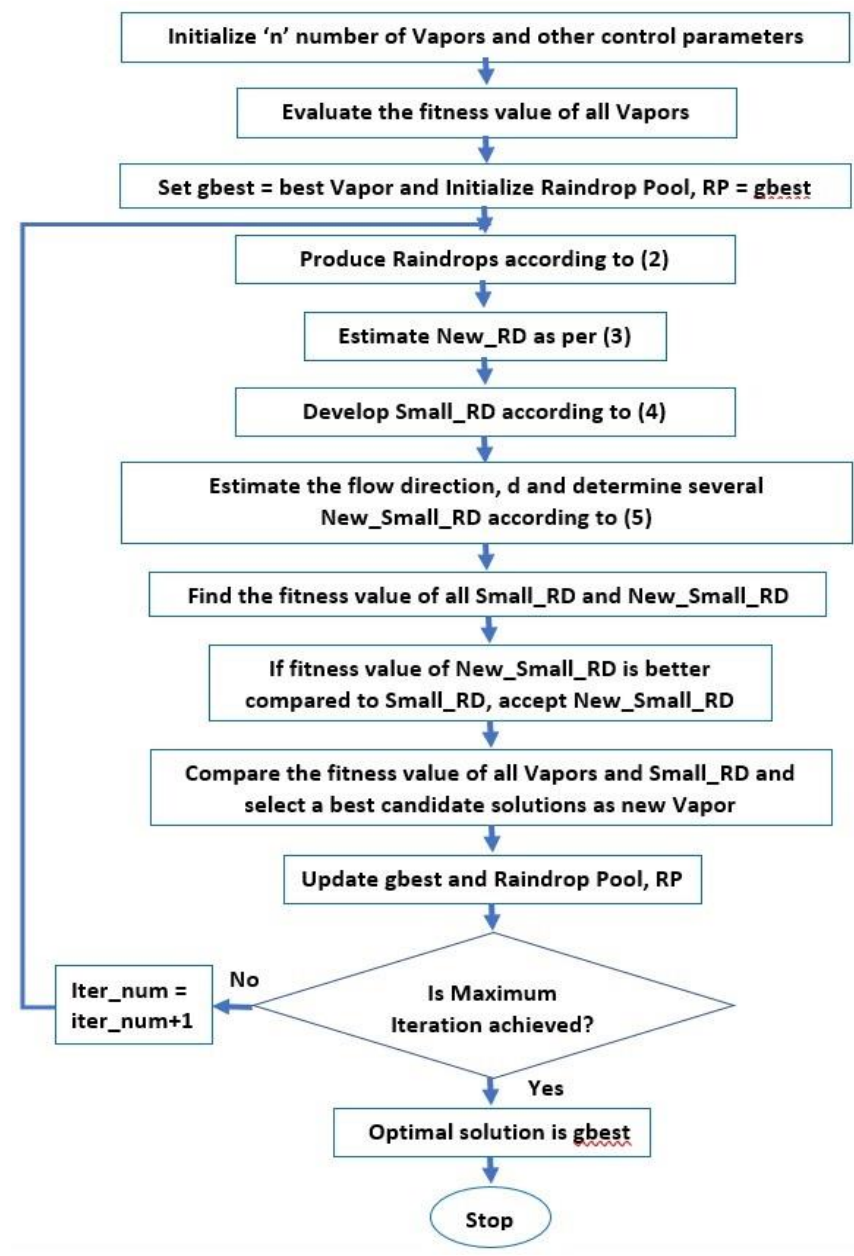

Figure 5. Flowchart of ARA

For SRM control, the means of utilizing ARA for the ideal tuning of PI are as per the following:

Stage 1: Arbitrarily introduce the hunt space with a populace of ' $n$ ' number of Vapours. The relating position of every Vapour is presented in (7). Chosen estimations of control boundaries are as per the following $\mathrm{n}=2$, most extreme emphasis cycle $=200$, venture boundaries $\tau_{-} 1=\tau_{-} 2=2$, Max_Flow_Number $=6$, greatest estimation of coefficient $=4$, and least estimation of coefficient $=-1$.

Stage 2: Govern the fitness of entire Vapours. Assume gbest $=$ best Vapour and RP = gbest.

Stage 3: Produce RD as indicated by (3) as the function of Vapour.

Stage 4: Create New_RD as per (4) as the role of RD.

Stage 5: Estimate Small_RD as an element of New_RD and Vapour as per (5).

Stage 6: Decide the moving track, d as per (13), and compute New_Small_RD as per (9) as the capacity of Small_RD and d.

Stage 7: Govern the aptness value of New_Small_RD and Small_RD. On the off chance that the error aptness of the previous is greater than the last mentioned, the streaming direction (d) is not right, and the New_Small_RD is disregarded. Be that as it may, all the Small_RDs are permitted to stream dependent on the fixing of Max_Flow_Number.

Stage 8: Based on the fitness standards of vapour and Small_RD, choose the finest ' $n$ ' amount of applicant resolutions as the new vapour. Additionally, apprise the gbest and RP.

Stage 9: Switch to stage 3 till maximum repetitions are touched.

Stage 10: Announce the gbest as the best solution.

\section{SIMULATION RESULTS AND ANALYSIS}

Performance of the proposed drive is analysed using 8/6 SRM built-in matlab. Parameters of analysed motor is presneted in Table 3. Torque ripple of SRM is analysed under various speeds and various

Torque ripple and noise control of switched reluctance motor using an adaptive fuzzy PI ... (Rekha P. S.) 
loads. The speed performance of SRM is analyzed in the aspects of peak overshoot, Steady-state error, speed ripple, speed drop during change in load and restoration time after change in load. Torque performance of SRM is analyzed in the aspects of steady-state error and torque ripple. Settling time of speed and torque is also discussed. In the aspect of electric vehicle performance of drive is analyzed under various speeds and variable load.

Table 3. Parameters of the motor analysed

\begin{tabular}{lc}
\hline \multicolumn{1}{c}{ Parameters } & Values \\
\hline Number of stator poles & 8 \\
Number of rotor poles & 6 \\
Stator resistance & $3.1 \Omega$ \\
Maximum current & $10 \mathrm{~A}$ \\
Maximum flux linkage & 0.486 \\
\hline
\end{tabular}

Case 1, in this case, motor speed is set to 1000 RPM and starts with the no load then load is increased to $7 \mathrm{Nm}$ at $2 \mathrm{~s}$. Speed and torque Performance of FGS-PI based DTC of SRM under Case 1 is shown in Figure 6.

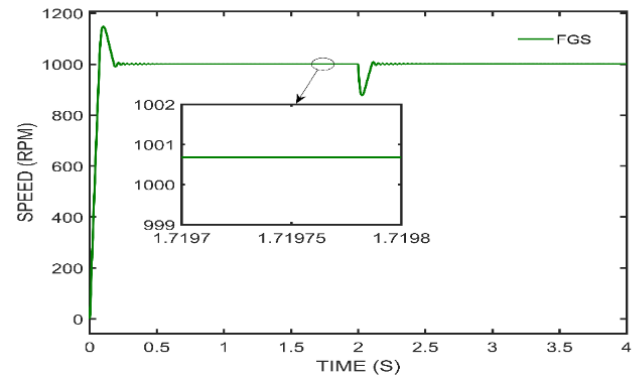

(a)

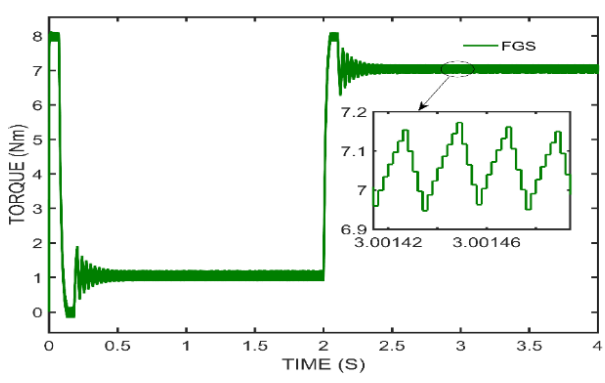

(b)

Figure 6. (a) Speed and (b) Torque performance of FGS-PI based DTC of SRM under case 1

From Figure 6, it is analyzed that the FGS controlled drive settles to the speed of 1000.74 RPM at $0.45 \mathrm{~s}$, which produces a steady state error of $0.074 \%$. Oscillation in speed is known to be ripple exists in the range of $0.005 \%$. At the time of starting peak overshoot produced by FGS is $14.9 \%$. The influence of online tuning of torque reference using FGS settles torque around $7.061 \mathrm{Nm}$ at $0.55 \mathrm{~s}$, produces steady state error as $0.87 \%$ with the torque ripple ratio of $3.14 \%$. On the time of change in load, speed drops to $12.4 \%$ and the restoration time after change in load is $0.6 \mathrm{~s}$. Compared to DTC with PI torque ripple produced by FGS is reduced.

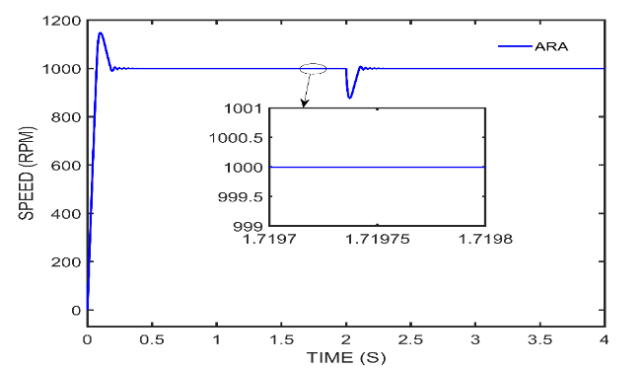

(a)

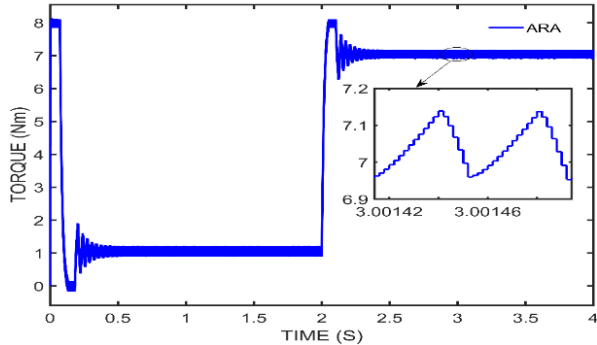

(b)

Figure 7. (a) Speed and (b) Torque performance of ARA based DTC of SRM under case 1 
In Figure 7(a) performance of ARA in the aspect of speed shows that the ARA settles the speed of $1000 \mathrm{RPM}$ at $0.4 \mathrm{~s}$, whereas the settling time by FGS is $0.45 \mathrm{~s}$. It shows that FGS takes more time for settling the speed than ARA. The steady state error produced in ARA is 0 which is absolutely error free compared to FGS. Moreover, the ripple ratio of the speed by ARA is $0.004 \%$ which is also reduced than the FGS. Furthermore, the peak overshoot is $14.83 \%$ whereas the FGS produces $14.9 \%$. On the time of change in load, speed drops to $12.38 \%$ which is $0.02 \%$ less than the FGS and the restoration time after load change is $0.49 \mathrm{~s}$ which is also better than FGS. The analysis shows the ARA has better performance in all the considered aspects.

From Figure 7(b), it is noted that the torque settles in $7.05 \mathrm{Nm}$ at $0.5 \mathrm{~s}$, whereas the FGS takes $0.55 \mathrm{~s}$ to settle the torque. The steady state error produced in ARA is $-0.71 \%$ which is comparatively less than the FGS. ARA based optimal tuning of PI for torque reference reduces the ripple ratio to $2.54 \%$, which is also less than the FGS. In this case, the torque performance of ARA is better than FGS in all the considered aspects. Comparative performance of FGS and ARA based DTC of SRM under case 1 is presented in Table 4.

Table 4. Comparative performance of FGS and ARA based DTC of SRM under case 1

\begin{tabular}{lcccc}
\multicolumn{1}{c}{ Parameters } & \multicolumn{2}{c}{ Speed (1000rpm) } & \multicolumn{2}{c}{ Torque (0 to 7 NM) } \\
& FGS & ARA & FGS & ARA \\
\hline Settling time (s) & 0.45 & 0.4 & 0.55 & 0.5 \\
Ripple ratio (\%) & 0.005 & 0.004 & 3.14 & 2.54 \\
Steady state error $(\%)$ & -0.074 & 0 & -0.87 & -0.71 \\
Peak overshoot $(\%)$ & 14.9 & 14.83 & - & - \\
Restoration time after load change (S) & 0.6 & 0.49 & - & - \\
Speed drop during change in load $(\%)$ & 12.4 & 12.38 & - & - \\
\hline
\end{tabular}

From an analysis of Case 1 both in speed and torque, the performance of ARA is better in all the aspects such as settling time, ripple ratio, steady state error, peak overshoot, Restoration time after load change and Speed drop during change in load.

Case 2, in case 2, motor speed set to 1000 RPM and starts with the load of $4 \mathrm{Nm}$ then raised to $7 \mathrm{Nm}$ at 2s. Speed and torque Performance of FGS-PI based DTC of SRM under Case 2 is shown in Figure 8.

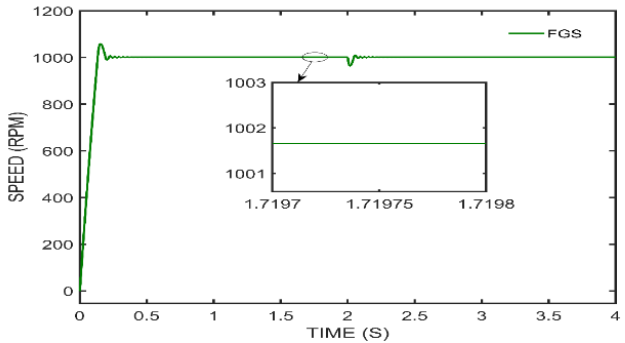

(a)

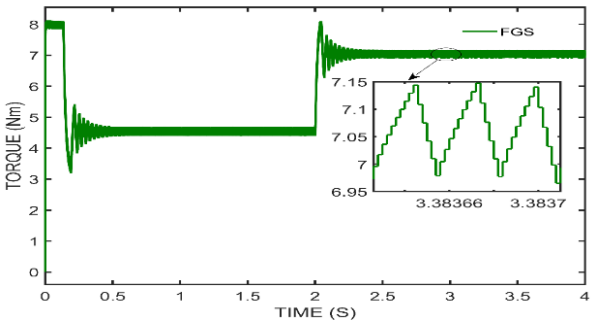

(b)

Figure 8. (a) Speed and (b)Torque performance of FGS -PI based DTC of SRM under case 2

From Figure 8, it is observed that the speed and torque are settled to $1001.7 \mathrm{RPM}$ and $7.055 \mathrm{Nm}$ at $0.65 \mathrm{~s}$ and $0.6 \mathrm{~s}$. In the aspect of speed, the FGS produces a steady state error of $-0.17 \%$ and on the aspects of the torque, FGS produces $-0.78 \%$ steady state error. Ripple ratio of speed and torque is reduced to $0.01 \%$ and $2.54 \%$ by FGS. In this case, the peak overshoot of the speed by FGS is $5.95 \%$. During change in load, speed drops to $3.7 \%$ and the restoration time after change in load is $0.5 \mathrm{~s}$. Speed and torque performance of ARA based DTC of SRM under case 2 is shown in Figure 9.

In Figure 9(a) the performance of ARA in the aspect of speed shows that the ARA settles the speed around 1000 RPM at $0.5 \mathrm{~s}$. The steady state error produced in ARA is absolute zero which is error free in contrast with FGS. Moreover, the ripple ratio is reduced to $0.004 \%$ by the influence of ARA, which is also better the FGS. Furthermore, the peak overshoot of the speed is 5.9\%, whereas the FGS produced $5.95 \%$. Speed drops during change in load is $3.7 \%$ which is similar to FGS and the restoration time after load change is $0.4 \mathrm{~s}$ which is improved than FGS. In this case, both FGS and ARA performed similarly in aspect of speed drop.

Torque ripple and noise control of switched reluctance motor using an adaptive fuzzy PI ... (Rekha P. S.) 
From Figure 9 (b), it is noted that the torque settles in $7.053 \mathrm{Nm}$ at $0.5 \mathrm{~s}$, whereas the FGS takes $0.65 \mathrm{~s}$ to settle the torque. It shows that the settling time of speed and torque by ARA is same. The steady state error produced in ARA is $-0.76 \%$ which is comparatively less than the FGS. The ARA reduces the ripple ratio up to $2.04 \%$, which shows improved performance of optimization. In this case, the torque performance of ARA is better than FGS in all the considered aspects. Comparative performance of FGS and ARA based DTC of SRM under case 2 is presented in Table 5.

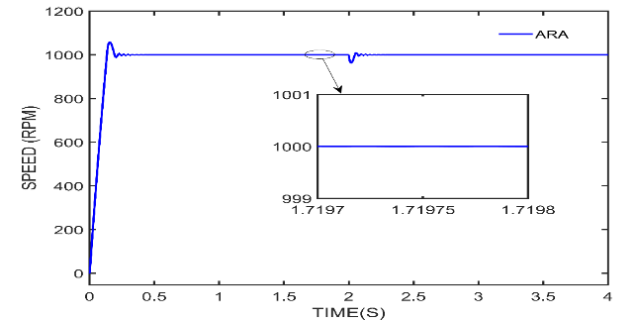

(a)

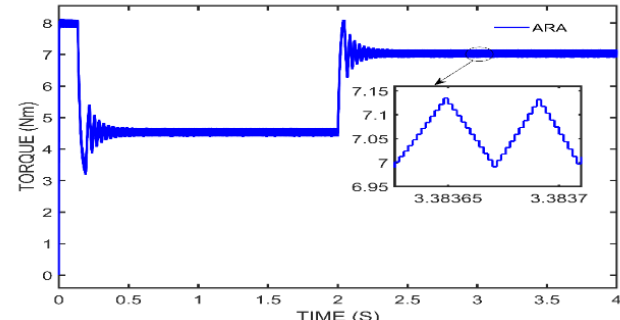

(b)

Figure 9. (a) Speed and (b) Torque performance of ARA based DTC of SRM under case 2

Table 5. Comparative performance of FGS and ARA based DTC of SRM under case 2

\begin{tabular}{lcccc}
\multicolumn{1}{c}{ Parameters } & \multicolumn{2}{c}{ Speed } & \multicolumn{2}{c}{ Torque } \\
& FGS & ARDA & FGS & ARDA \\
\hline Settling time (s) & 0.65 & 0.5 & 0.62 & 0.5 \\
Ripple ratio (\%) & 0.01 & 0.004 & 2.54 & 2.04 \\
Steady state error (\%) & -0.17 & 0 & -0.78 & -0.76 \\
Peak overshoot $(\%)$ & 5.95 & 5.9 & - & - \\
Restoration time after load change (S) & 0.5 & 0.4 & - & - \\
Speed drop during change in load $(\%)$ & 3.7 & 3.7 & - & - \\
\hline
\end{tabular}

The speed and torque performance of both the controllers are observed for Case 2. Performance of ARA is better in ripple ratio, steady state error and peak overshoot. Both controllers possess the same performance in settling the time for speed and torque.

Case 3, in this case, the motor speed set to 1300 RPM and starts with the load of $4 \mathrm{Nm}$ then raised to7Nm at 2s. Speed and torque Performance of FGS-PI based DTC of SRM under Case 3 is shown in Figure 10. It is observed that the speed and torque are settled to $1002.9 \mathrm{RPM}$ and $7.38 \mathrm{Nm}$ at $0.71 \mathrm{~s}$ and $0.6 \mathrm{~s}$. Steady state error produced in this case for speed is $-0.29 \%$ and in the torque is $-5.31 \%$. Ripple ratio of speed and torque is $0.015 \%$ and $2.97 \%$. In this case, the peak overshoot of the speed is $4.05 \%$ by FGS. Speed drop during change in load is $2.92 \%$ and the restoration time after change in load is $0.4 \mathrm{~s}$.

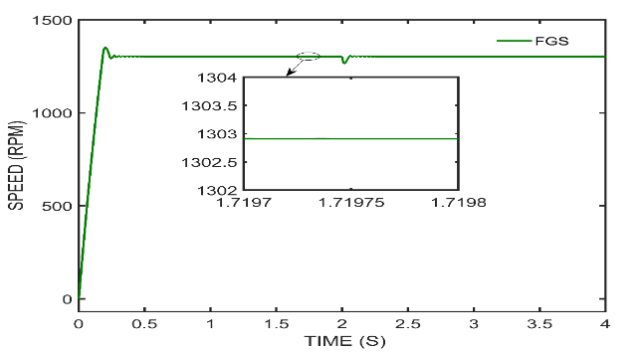

(a)

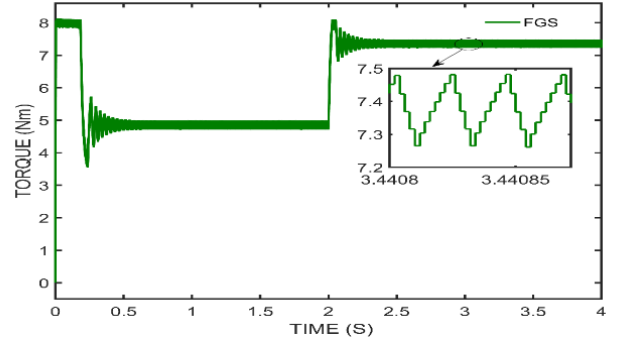

(b)

Figure 10. (a) Speed and (b)Torque performance of FGS -PI based DTC of SRM under case 3

Speed and torque Performance of ARA based DTC of SRM under case 3 is shown in Figure 11. From Figure 11(a), it is obvious that the ARA settles the speed in 1300 RPM at 0.66s, whereas the FGS settles the speed at $0.71 \mathrm{~s}$. It shows that settling time of speed is reduced by proposed ARA compared to FGS. 
The steady state error and ripple ratio produced in ARA is absolute zero and $0.0092 \%$ which is better than the FGS. The peak overshoot of the speed by ARA is $3.98 \%$ whereas the FGS produced $4.05 \%$. On the time of change in load, speed drops to $2.92 \%$ which is similar to FGS but the restoration time after load change is $0.35 \mathrm{~s}$ which is better than FGS. It shows the ARA has improved performance in almost all the aspects.

From Figure 11(b), it is noted that the torque settles in $7.368 \mathrm{Nm}$ at $0.55 \mathrm{~s}$, whereas the FGS takes $0.6 s$ to settle the torque. It shows that the ARA settles the speed in a quick manner. The steady state error and ripple ratio produced by an ARA in torque is $-5.31 \%$ and $2.5 \%$. Both are comparatively less than the FGS based DTC. In this case, the torque performance of ARA is improved compared to FGS.

From case 3, the overall performance of FGS and ARA is analysed. Both in speed and torque, the performance of ARA is better in all the considered aspects such as settling time, ripple ratio, steady state error and peak overshoot. Compared to previous cases peak overshoot in speed is reduced in case 3, while steady state error in torque is increased. Comparative performance of FGS and ARA based DTC of SRM under case 3 is presented in Table 6.

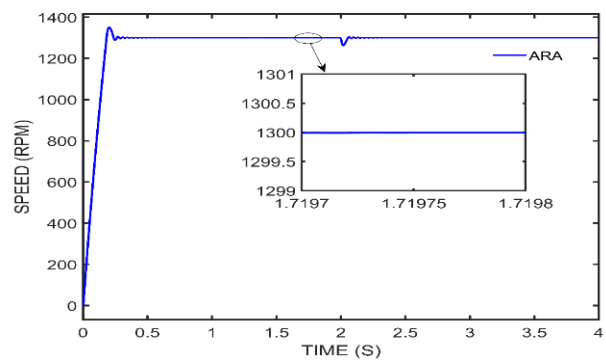

(a)

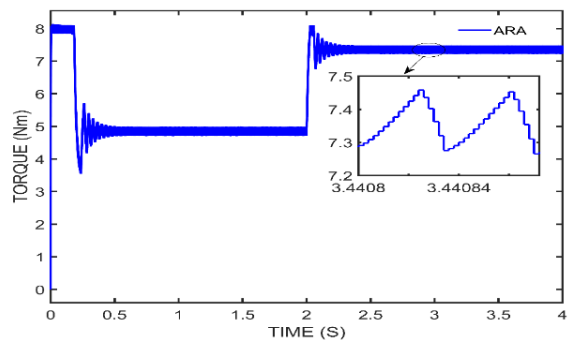

(b)

Figure 11. (a) Speed and (b) Torque performance of ARA based DTC of SRM under case 3

Table 6. Comparative performance of FGS and ARA based DTC of SRM under Case 3

\begin{tabular}{lcccc}
\hline \multicolumn{1}{c}{ Parameters } & \multicolumn{2}{c}{ Speed } & \multicolumn{2}{c}{ Torque } \\
& FGS & ARDA & FGS & ARDA \\
\hline Settling time (s) & 0.71 & 0.66 & 0.6 & 0.55 \\
Ripple ratio (\%) & 0.015 & 0.0092 & 2.97 & 2.5 \\
Steady state error (\%) & -0.29 & 0 & -5.31 & -5.26 \\
Peak overshoot (\%) & 4.05 & 3.98 & - & - \\
Restoration time after load change (S) & 0.4 & 0.35 & - & - \\
Speed drop during change in load (\%) & 2.92 & 2.92 & - & - \\
\hline
\end{tabular}

Case 4, in case 4, motor speed is set to 1500 RPM and starts with the load of $4 \mathrm{Nm}$ then raised to7Nm at 2 s. Speed and torque performance of FGS-PI based DTC of SRM under case 4 is shown in Figure 12.

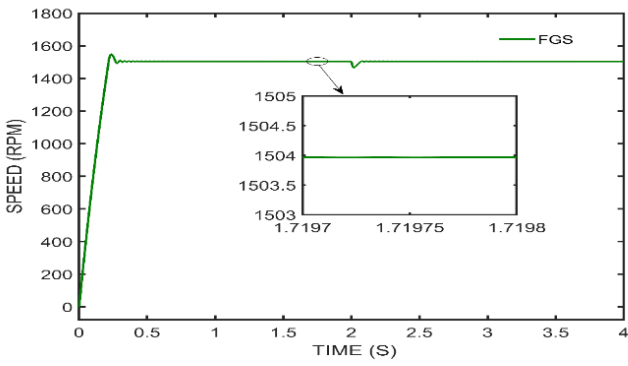

(a)

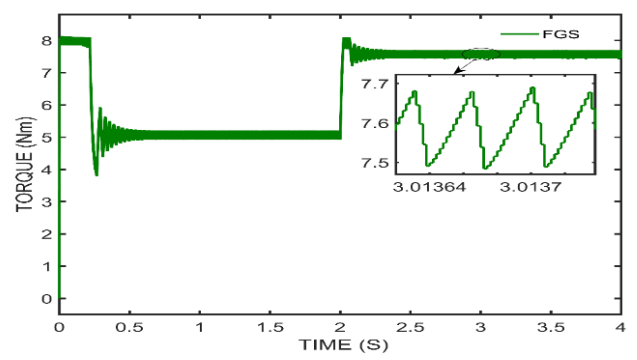

(b)

Figure 12. (a) Speed and (b)Torque performance of FGS -PI based DTC of SRM under case 4 
From Figure 12, the settling value of speed is $1504 \mathrm{RPM}$ at $0.7 \mathrm{~s}$ with the peak overshoot is $3.21 \%$. FGS based system settles torque to $7.588 \mathrm{Nm}$ at $0.65 \mathrm{~s}$. Steady state error of speed and torque are $-0.27 \%$ and 8.4\%. From Figure 12(a) it is observed that the FGS reduces the ripple ratio of the speed is known to be $0.0333 \%$. Ripple ratio developed in torque by using FGS is $2.7 \%$, which is slightly higher compared to case 2. During change in load, speed drops to $2.53 \%$ and the restoration time after change in load is $0.5 \mathrm{~s}$

Figure 13(a) shows that the ARA settles the speed in $1500 \mathrm{RPM}$ at $0.62 \mathrm{~s}$, which is $0.12 \mathrm{~s}$ less than FGS speed settling time. It reveals that ARA has offered improved performance in settling the speed. The steady state error produced by ARA is absolute zero. In all the cases the steady state error of the ARA is absolute zero which is error free compared with FGS. Ripple ratio of the speed by using ARA is $0.0100 \%$ which is comparatively better than the FGS. Furthermore, the peak overshoot of the speed is 3.13\%, whereas the FGS produced $3.21 \%$. Speed drops during change in load is $2.53 \%$ which is similar to FGS and the restoration time after load change is $0.4 \mathrm{~s}$ which is improved than FGS.

From Figure 13(b), it is observed that the torque settles in $7.576 \mathrm{Nm}$ at $0.6 \mathrm{~s}$, whereas the FGS takes $0.7 \mathrm{~s}$ to settle the torque. It shows the ARA has improved performance in settling the torque. The steady state error produced in ARA is $-8.23 \%$ which is comparatively less than the FGS. Torque ripple ratio is reduced to $2.32 \%$ by the influence of ARA, which is better than the FGS. In this case, the torque performance of ARA shows better in almost all the considered aspects. Comparative performance of FGS and ARA based DTC of SRM under case 4 is presented in Table 7.

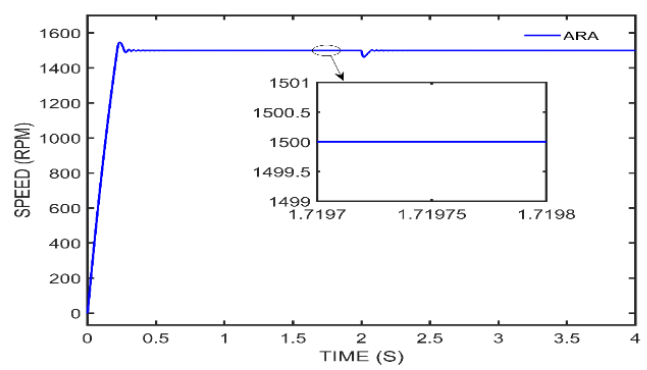

(a)

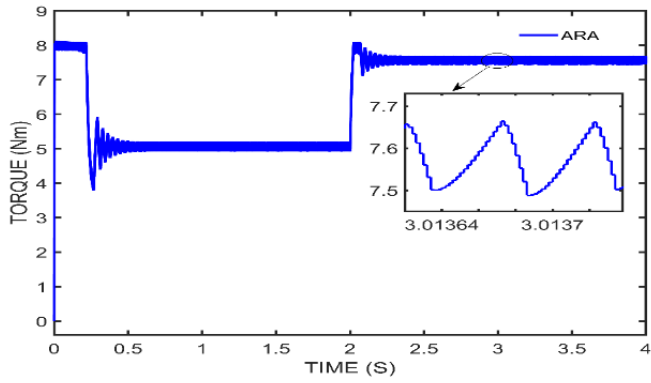

(b)

Figure 13. (a) Speed and (b)Torque performance of ARA based DTC of SRM under case 4

Table 7. Comparative performance of FGS and ARA based DTC of SRM under case 4

\begin{tabular}{lcccc}
\hline \multicolumn{1}{c}{ Parameters } & \multicolumn{2}{c}{ Speed } & \multicolumn{2}{c}{ Torque } \\
& FGS & ARDA & FGS & ARDA \\
\hline Settling time (s) & 0.7 & 0.62 & 0.65 & 0.6 \\
Ripple ratio (\%) & 0.0333 & 0.0100 & 2.7 & 2.32 \\
Steady state error $(\%)$ & -0.27 & 0 & -8.4 & -8.23 \\
Peak overshoot $(\%)$ & 3.21 & 3.13 & - & - \\
Restoration time after load change (S) & 0.5 & 0.4 & - & - \\
Speed drop during change in load (\%) & 2.53 & 2.53 & - & - \\
\hline
\end{tabular}

From the results of Case 4, both in speed and torque, the performance of ARA has improved performance in all aspects such as settling time, ripple ratio, steady state error and peak overshoot. From the analysis of various of cases of speed and load, it is observed that ARA has better performance than FGS in speed in the aspects of settling time, ripple ratio, peak overshoot and restoration time almost under all cases. Steady state error in speed is absolutly eliminated with the aid of ARA under all cases with load and without load. Speed drop during change in load is almost same in both controllers. Under all cases performance of torque using ARA is enhanced compared to FGS in the aspects of settling time, ripple ratio and steady state error. Comparative performance of the proposed system with the existing system in the aspect torque ripple reduction is presented in Table 8 .

From Table 8, it is clear that analysed ARA-PI and FGS-PI based DTC of SRM offered less torque ripple compared to the existing PI and GA-PI based DTC of SRM. FGS tuned PI in DTC reduces 69.32\% of torque ripple compared DTC with PI, while proposed ARA optimised PI minimises torque ripple around $74 \%$. Reduction in torque ripple with the help od ARA based DTC minimises acoustic noise of SRM. 
Table 8. Comparative performance of torque ripple

\begin{tabular}{lc}
\hline \multicolumn{1}{c}{ Controller } & Torque ripple (\%) \\
\hline DTC with PI & 8.8 \\
DTC with genetic PI & 6.9 \\
DTC with FGS- PI & 2.7 \\
DTC with ARA PI & 2.32 \\
\hline
\end{tabular}

\section{CONCLUSION}

In this paper, acoustic noise control of SRM in electric vehicle is analysed by means of torque ripple control. Artificial raindrop algorithm is proposed in direct torque control of SRM, to minimise torque ripple. Performance of the proposed system is compared with the fuzzy gain scheduling PI based direct torque control of SRM under various speeds and various loads. Direct torque control of SRM employs PI controller to develop torque reference for converter control, to enhance the performance of a drive, in this article FGS and ARA controllers are applied to tune the gains of PI controller. Precise tuning of torque reference in DTC results reduced torque ripple. Analysis of proposed system revealed that it reduces around $74 \%$ torque ripple compared to PI based DTC, which makes drive most suitable for electric vehicles . Various case of analysis validates that proposed system not only enhances torque performance it also enriches speed performance, while both speed and torque qualities are manditory for electric vehicles. Speed performance in the aspects of peak overshoot, settling time, steady state error, ripple and restoration time confirms that under all cases proposed ARA based DTC offered improved performance compared to FGS. Therefore by employing proposed ARA based DTC, noise control by means of ripple control is achieved with enhanced speed performance.

\section{ACKNOWLEDGEMENTS}

The authors would like to thank the Research center, Department of ECE, SJBIT, Affiliated to Visvesvaraya Technological University, Belagavi-590018, Karnataka, India for their support in this research.

\section{REFERENCES}

[1] Hua, W., Zhao, G., Hua, H. and Cheng, M., "General power equation of switched reluctance machines and power density comparison," IEEE Transactions on Industry Applications, vol. 53, no. 5, pp.4298-4307, 2017, DOI: 10.1109/TIA.2017.2700476.

[2] K. w. Hu, P. H. Vi, and C. M. Liaw, "An EV SRM drive powered by battery/supercapacitor with G2V and V2HIV2G capabilities," IEEE Trans. Ind Electron., vol. 62, no. 8, pp. 4714-27, 2015, DOI: 10.1109/TIE.2015.2396873.

[3] Hu Y, Gan C, Cao W, Zhang J, Li W, and Finney SJ, "Flexible fault-tolerant topology for switched reluctance motor drives," IEEE Transactions on Power Electronics, vol. 31, no. 6, pp. 4654-4668, 2016, DOI: 10.1109/TPEL.2015.2477165.

[4] Rahman KM, Fahimi B, Suresh G, Rajarathnam AV, and Ehsani M, "Advantages of switched reluctance motor applications to EV and HEV: Design and control issues," IEEE Transactions on Industry Applications, vol. 36, no. 1, pp. 111-121, 2000, DOI: 10.1109/28.821805.

[5] Tursini M, Villani M, Fabri G, and Di Leonardo L., "A switched-reluctance motor for aerospace application: Design, analysis, and results," Electric Power Systems Research, vol. 142, pp. 74-83, 2017, DOI: 10.1016/j.epsr.2016.08.044.

[6] V. Valdivia, R. Todd, F. 1. Bryan, A. Barrado, A. Lazaro, and A. 1. Forsyth, "Behavioralmodeling of a switched reluctance generator for aircraft power systems," IEEE Transactions on Industrial Electronics, vol. 61, no. 6, pp. 2690-2699, 2014, DOI: 10.1109/TIE.2013.2276768.

[7] D. Choi, S. Byun, and Y. Cho, "A study on the maximum power control method of switched reluctance generator for wind turbine," IEEE Transactions on Magnetics, vol. 50, no. 1, pp. 1-4, 2014, DOI: 10.1109/TMAG.2013.2274174.

[8] J. Pan, Y. Zou, N. Cheung, and G. Cao, "On the voltage ripple reduction control of the linear switched reluctance generator for wave energy utilisation," IEEE Transactions on Power Electronics, vol. 29, no. 10, pp. 5298-5307, Oct. 2014, DOI: 10.1109/TPEL.2013.2292069.

[9] Wang X, Gan C, Hu Y, Cao W, and Chen X., "Renewable energy-fed switched reluctance motor for PV pump applications," 2014 IEEE Conference and Expo Transportation Electrification Asia-Pacific (ITEC Asia-Pacific), 2014, pp. 1-6, DOI: 10.1109/ITEC-AP.2014.6940869.

[10] Dursun, M., "A Wheelchair Driven with Fuzzy Logic Controlled Switched Reluctance Motor Supplied by PV Arrays," Journal of Applied Sciences, vol. 8, no. 19, pp. 3351-3360, 2008, DOI: 10.3923/jas.2008.3351.3360.

[11] Chai, J.Y., Lin, Y.W. and Liaw, C.M., "Comparative study of switching controls in vibration and acoustic noise reductions for switched reluctance motor," IEE Proceedings-Electric Power Applications, vol. 153, no. 3, pp.348360, 2006, DOI: 10.1049/ip-epa:20050340. 
[12] Yoshida M, Murai Y, and Takada M., "Noise reduction by torque ripple suppression in brushless DC motor," PESC 98 Record. 29th Annual IEEE Power Electronics Specialists Conference (Cat. No.98CH36196), 1998, pp. 13971401 vol.2, DOI: 10.1109/PESC.1998.703225.

[13] XudongGao, XudongWang, ZhongyuLi, and YongqinZhou," A Review of Torque Ripple Control Strategies of Switched Reluctance Motor," International journal of control and automation, vol.8. no.4, pp. 103-116, 2015, DOI: 10.14257/ijca.2015.8.4.13.

[14] Mahalakshmi G and Ganesh C, "A Review of Torque Ripple Control Strategies of Switched Reluctance Motor," International Journal of Applied Engineering Research, vol. 13, no. 7, pp. 4688-4692, 2018.

[15] Ronanki D and Parthiban P., "PV-battery powered direct torque controlled switched reluctance motor drive," 2012 Asia-Pacific Power and Energy Engineering Conference, 2012, pp. 1-4, DOI: 10.1109/APPEEC.2012.6307172.

[16] Jing J, Lv S and Fang Shi C, "Direct torque PID control of switched reluctance motor based on duty ratio control technique," 2015 IEEE International Conference on Mechatronics and Automation (ICMA), 2015, pp. 649-653, DOI: 10.1109/ICMA.2015.7237561.

[17] Fahas S, Le-Huy H and Kamwa I., "Fuzzy direct torque control of switched reluctance motors," IECON 2012-38th Annual Conference on IEEE Industrial Electronics Society, 2012, pp. 1811-1816, DOI: 10.1109/IECON.2012.6388926.

[18] Shang C, Xu A, Huang L and Chen J., "Flux linkage optimisation for direct torque control of switched reluctance motor based on model predictive control," IEEJ Transactions on Electrical and Electronic Engineering, vol. 14, no. 7, pp. 1105-13, 2019, DOI: 10.1002/tee.22906.

[19] Srinivas P, Prasad PVN, "PWM Control of Asymmetrical Converter Fed Switched Reluctance Motor Drive," in Proceedings of the World Congress on Engineering and Computer Science 2013, vol. 1, pp. 283-288, 2013.

[20] Shah V, Alam M, and Payami S., "High Torque/Ampere Direct Torque Control of Switched Reluctance Motor Drives," 2019 National Power Electronics Conference (NPEC), 2019, pp. 1-6, DOI: 10.1109/NPEC47332.2019.9034777.

[21] Yan N, Cao X, done Deng Z., "Direct torque control for switched reluctance motor to obtain high torque-ampere ratio," IEEE Transactions on Industrial Electronics, vol. 66, no. 7, pp. 5144-5152, July 2019, DOI: 10.1109/TIE.2018.2870355.

[22] Cheok AD and Fukuda Y., "A new torque and flux control method for switched reluctance motor drives," IEEE Transactions on Power Electronics, vol. 17, no. 4, pp. 543-557, July 2002, DOI: 10.1109/TPEL.2002.800968.

[23] Justice AV, Kathyaini C., "Controlling of nonlinear systems by using fuzzy logic controller," International Research Journal of Engineering and Technology, vol. 2, no. 7, pp. 648-656, 2015.

[24] Rajeev GajananSapre, "On Fuzzy Logic to handle Vague and Imprecise Data," International Journal of Software \& Hardware Research in Engineering, vol. 3, no. 9, pp. 75-80, 2015.

[25] Ahmad S, Ali S, Tabasha R., "The design and implementation of a fuzzy gain scheduled PID controller for the Festo MPS PA compact workstation liquid level control," Engineering Science and Technology, an International Journal, vol. 23, no. 2, pp. 307-315, 202o, DOI: 10.1016/j.jestch.2019.05.014.

[26] Chaiyatham T, and Ngamroo I., "Optimal fuzzy gain scheduling of PID controller of superconducting magnetic energy storage for power system stabilisation," International journal of innovative computing, information and control, vol. 9, no. 2, pp. 651-66, 2013.

[27] Chaple, M., Bodkhe, S.B., and Daigavane, P., "Four phases (8/6) SRM with DTC for minimization of torque ripple," The International Journal of Electrical Engineering \& Education, 2019, DOI: $10.1177 / 0020720919841686$

[28] Divandari M. and Rezaie B., "Fuzzy Logic Control of Switched Reluctance Motor Drives," in New Applications of Artificial Intelligence, 2016, p. 59.

[29] Elmas C. and Yigit T., "Genetic algorithm based online tuning of a PI controller for a switched reluctance motor drive," Electric power components and systems, vol. 35, no. 6, pp. 675-691, 2007, DOI: 10.1080/15325000601139674.

[30] Jeong BH, Lee KY, Na JD, Cho GB, and Baek HL, "Direct torque control for the 4-phase switched reluctance motor drives," 2005 International Conference on Electrical Machines and Systems, 2005, pp. 524-528 Vol. 1, DOI: 10.1109/ICEMS.2005.202584.

[31] Mahata S, Saha SK, Kar R, and Mandal D., "Artificial raindrop algorithm-based design of wideband IIR fractional order digital integrators," Iranian Journal of Science and Technology, Transactions of Electrical Engineering, vol. 41, no. 3, pp. 165-173, 2017, DOI: 10.1007/s40998-017-0025-5. 


\section{BIOGRAPHIES OF AUTHORS}

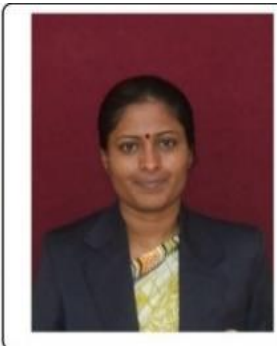

Mrs.Rekha P S obtained B.E.(E\&EE) from Mangalore University and M.Tech. from VTU, Karnataka, 2010. She is pursuing her Research currently on Power Electronics and Drives under the guidance of Dr. Vijayakumar, Professor, Department ECE, SJBIT, Bangalore. She has published many research articles in reputed journals and presented papers in National and International conferences.

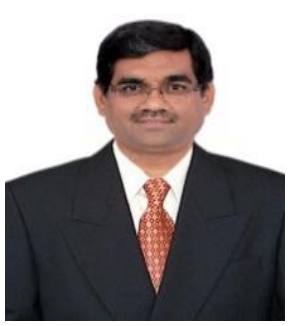

Dr. Vijayakumar T obtained B.E(Electronics), M.E (Digital Communication) from the Bangalore University and $\mathrm{PhD}$ (VLSI and Image Processing) from Kuvempu University. He served as a Lecturer, Assistant Professor, Associate Professor in various colleges. Presently working as a Professor in the Dept. Of ECE, SJB Institute of Technology, Bengaluru. He has served as BOE for Visveswaraya Technological University. He has published many Journals and conference papers to his credit. 